\title{
Topics, assertions, and additive words: how L2 learners get from information structure to target-language syntax*
}

CHRISTINE DIMROTH

Abstract

The article compares the integration of topic-related additive words at different stages of untutored L2 acquisition. Data stem from an "additive-elicitation task" that was designed in order to capture topic-related additive words in a context that is at the same time controlled for the underlying information structure and nondeviant from other kinds of narrative discourse.

We relate the distinction between stressed and nonstressed forms of the German scope particles and adverbials auch 'also', noch 'another', wieder 'again', and immer noch 'still' to a uniform, information-structure-based principle: the stressed variants have scope over the topic information of the relevant utterances. It is then the common function of these additive words to express the additive link between the topic of the present utterance and some previous topic for which the same state of affairs is claimed to hold. This phenomenon has often been referred to as "contrastive topic," but contrary to what this term suggests, these topic elements are by no means deviant from the default in coherent discourse.

In the underlying information structure, the validity of some given state of affairs for the present topic must be under discussion. Topic-related additive words then express that the state of affairs indeed applies to this topic, their function therefore coming close to the function of assertion marking. While this functional correspondence goes along with the formal organization of the basic stages of untutored second-language acquisition, its expression brings linguistic constraints into conflict when the acquisition of finiteness pushes learners to reorganize their utterances according to target-language syntax.

\section{Introduction}

The meaning of focus particles, that is, words like English also, only, even, is commonly assumed to affect the focus component of an utterance 
(e.g. König 1991). This assumption seems to follow neatly from the way focus particles interact with contrastive information: their meaning contribution can only be interpreted if they apply to a piece of information that is contrasted with a (often contextually given) set of alternatives. This is typically the case with focused information, and these particles then specify the relation between the focused element and other elements of the set of alternatives as being additive, restrictive, etc. (1) is an example of an additive (scalar) particle applied to the focus information of an utterance. The domain of application, that is, the element(s) actually affected by the additive meaning of the particle, are marked by square brackets.

(1) Q: How did her parents react to the news?

a. Well, they didn't worry too much,

b. and they even [offered all kinds of concrete help].

Disregarding for the moment the various definitions of focus, its relation to these particles seems to be so tight that it has frequently been referred to as "the focus of the particle" (e.g. König 1991: 12). This view has been challenged by Dimroth and Klein (1996), who argue that focus particles indeed interact with the focus of an utterance, but they also point out that the origin of the focus structure of an utterance is completely independent of the actual presence of a particle.

The present paper is based on the observation that some focus particles, namely the additive ones, often do not apply to the focus but to the topic of utterances in context. This can easily be seen in question-answer pairs where the complex topic of the question is divided up into individual referents in the answer:

(2) Q: How did her parents react to the news?

a. Well, her mother didn't worry too much,

b. and [her father] seemed to take it quite well, too.

The question in (2) asks for the specification of some state of affairs that held true of the topic "her parents" at some moment in the past. If, for whatever reason, the answer separately specifies two such states of affairs for the individual elements of the question topic, and furthermore, if these two states of affairs are conceived of as sufficiently similar, the speaker can then apply an additive particle to the second of these (contrastive) topic elements (cf. [2b]).

This case of clear information distribution might seem a bit odd. ${ }^{1}$ However, a similar kind of information structure, that is, a similar distribution of contrasted versus noncontrasted pieces of information, underlies many common sequences of utterances, as in example (3). 
(3) a. Yesterday I went to that workshop on language acquisition.

b. [Paul] was there, too.

b'. [Today] I'm going, too.

In examples (2) and (3), one state of affairs ('to take it well', 'to go to this workshop') is claimed to hold for two different topic elements (entities or time spans talked about). In (2a) and (3a) it is asserted to be true for one of them, and in the following (2b) and (3b) utterances the additive particle is mediating the validity of this state of affairs for a different topic entity, (2b) and (3b), or topic time, $\left(3 b^{\prime}\right)$. The kind of information structure underlying the utterances in $(2 b)$ and $(3 b)$ therefore assigns the particles the role of a mediating device between a given state of affairs and some (contrastive) topic.

In some languages like German and Dutch, where genuine focus particles (as in [1]) remain normally unstressed, additive particles have to carry the main stress when they are applied to the topic part of an utterance. This is indicated by capitals in (4) and all following examples. ${ }^{2}$

(4) a. Gestern war ich bei diesem workshop über Spracherwerb.

'Yesterday I went to that workshop on language acquisition.'

b. [Paul] war $A U C H$ da.

'Paul was there, too.'

b'. [Heute] gehe ich $A U C H$ hin.

'Today, I'll go there, too.'

The goal of explaining this salient stress pattern has meant that the particle auch 'also' has been given much attention in the literature on German particles (e.g. Dimroth 1998; Kowalski 1992; Krifka 1999; Reis and Rosengren 1997). These observations are mainly based on questionanswer pairs like (2) or sequences like (4), since they seem to be a reliable means for the control of information structure.

In the present article, I shall report on a discourse-elicitation task that allows us to obtain natural production data that is nevertheless highly controlled with respect to information structure. This setup is related to the insight that not the sentence but the organization of coherent discourse is the appropriate context of analysis for additive particles (cf. Dimroth 1998; Watorek and Perdue 1999). Furthermore, I will be extending the analysis sketched above to other kinds of additive words that share the stress behavior of German auch, namely particles like noch 'another', or temporal adverbials, like wieder 'again' and immer noch 'still'.

My observations are based on data from native speakers and adult second-language learners of German. These production data are particu- 
larly interesting for the study of additive words, as it is well known that the surface structure of untutored learner varieties generally reflects the underlying information structure to a higher extent than fully fledged languages do. In the process of acquisition, the untutored L2 learner's reliance on information structure to construct utterances does of course decrease as the impact of target-language syntax increases. This is important since the predominant patterns of utterance organization at the different stages of acquisition also shape the options for the integration of additive words and other optional elements into these structures.

The acquisition of finiteness has been shown to be of particular importance for the impact of information structure and target-language syntax (Klein and Perdue 1997) and, as a consequence, for the stepwise integration of additive words (Benazzo 2000; Dimroth and Watorek 2000). I shall therefore focus on an acquisition stage that is characterized by a nonfinite utterance organization. This stage, the so-called "basic variety," is characterized by a restricted number of phrasal patterns and some basic semantic and pragmatic constraints (see Klein and Perdue 1992, 1997 for a detailed description). I shall also deal with the developmental steps toward more advanced varieties based on finite utterance organization.

The paper is organized as follows: I shall first outline (in section 2) what I mean by information structure and how I define the parts that seem to be crucial for an understanding of additive words with topical domains of application. Then in section 3, the meaning and structural integration of topic-related additive words in German will be addressed. Section 4 discusses the relation between the function of topic-related additive words and the function of assertion marking with the help of finiteness. It is argued that the expression of both functions runs into conflict with the linguistic means available to the learner at some point in the process of L2 acquisition. The next two sections are devoted to an empirical study of additive words in the varieties of untutored L2 learners in comparison to native speakers of German: section 5 describes the method of data elicitation and section 6 contains the results of the study. Conclusions are given in section 7.

\section{Information structure and contrastive topics}

In the previous section it was stated that additive words are sensitive to the underlying information structure of an utterance in context. In this approach, the term information structure covers two types of relationship. First it is used to describe the relationship between an information unit 
(e.g. topic) and the utterance as a whole (this kind of syntagmatic relationship might be called aboutness). Second, the term describes the relationship between an information unit of a given utterance (e.g. topic) with respect to the same information unit in a previous utterance (this paradigmatic relationship can be characterized by contrastiveness).

In order to understand the way in which additive words interact with certain information components, both relations have to be taken into account. As we have seen, additive words (like other particles) are a way of relating some piece of information and a set of alternatives. Contrastiveness seems, therefore, to be the basic condition for the domain of application of an additive word. But the existence of contrast does not depend on the additive words - it simply means that utterances normally differ from previous utterances in ongoing discourse. Such a difference may, but need not, imply new (in the sense of not yet introduced) information. As we have seen in examples (2)-(4), it might well be that a GIVEN situation or state of affairs is claimed to be true for DIFFERENT topic entities, which have previously been introduced.

At this point, the other kind of relationship comes into play. Contrastive or not, a topic has to contribute to the interpretation of the utterance as a whole; basically it serves to identify the situation the utterance is about (cf. Lambrecht 1994), or to anchor the utterance in context. As we shall see, this cuts down the types of contrast that are allowed for topics in a coherent discourse.

Form and function of contrastive topics in German have been extensively discussed in the literature (cf. Büring 1995; Jacobs 1997). The emphasis has been on the interpretation of the so-called "bridge accent," an accent pattern in which the contrastive topic is marked by a rising tone, while the focus of the utterance is recognized by a falling tone. Because of this salient intonation pattern, this phenomenon has also been referred to as "I-topicalization" (where I refers to intonation; cf. Jacobs 1997: 93). Even if no context is given, the bridge-accent contour evokes the search for some contrastive topic entity for which the given state of affairs might hold true. Consider example (5) from Büring (1995):

(5) Q: Hat deine Frau andere Männer geküßt?

'Did your wife kiss other men?'

A: /MEIne Frau hat KEI $\backslash$ ne anderen Männer geküßt. 'MY wife DIdn't kiss other men.'

In order to shed light on these phenomena and other properties of contrastive topics (e.g. scope inversion), researchers have relied heavily on the discussion of isolated examples of the question-answer pair type, which tends to obscure the fact that this kind of information structure 
is an extremely frequent and common phenomenon in connected discourse.

The common denominator is that the validity of a given state of affairs with respect to some different topic must be under discussion. In examples like (5) the mere existence of a topic entity that might differ from the given one in respect to the validity of the state of affairs under discussion is evoked without ever really specifying it. In connected discourse, some state of affairs can be said to be true for a certain topic element in one utterance, and one of the subsequent utterances can then give an answer to the implicit question of whether the given state of affairs can possibly be valid for a different topic. In the positive case, an additive particle can be used to create an additive relation between the different topic elements for which the state of affairs holds true. This is also why these particles are so frequently attested in elliptic utterances (cf. ich auch 'me too'); just like other anaphoric elements, they refer back to given states of affairs, linking them to different actual topics. ${ }^{3}$

The kind of information structure underlying the examples (1)-(5) occurs frequently in connected discourse, but it is not always found in such a condensed form. This means that (i) there need not be an explicit question, as in the examples above, and (ii) the utterances linked by this additive relationship can be nonadjacent. This observation is important because it shows that locally there is nothing particular about these topic elements that are affected by additive particles; they can easily follow the default conditions for topic management in discourse. So (2) could be as follows:

(6) a. ihre/MUtter ist im wesentlichen RU $\backslash$ hig geblieben 'her mother basically kept calm'

b. und hat sie erstmal zu einer Schwangerschaftsberatung gebracht 'and took her to see a pregnancy counsellor'

c. abends ist sie dann mit ihrem Vater essen gegangen 'in the evening she went out for dinner with her father'

d. der hat sich die ganze Sache dann erstmal angehört 'he first listened to the whole story'

e. und $[\emptyset]$ hat es schließlich $A U C H \backslash$ ziemlich locker genommen 'and finally took it rather well, too'

The additive particle auch applies to the topic entity 'her father' that the second part of the discourse is about. This topic entity follows the local default conditions. It is introduced as a full noun in the focal part of (6c); maintained, promoted to a topic position, and referred to with a pronoun in (6d), and again maintained with the help of a zero anaphor in (6e). Still, this topic entity is the second one to which a given state of 
affairs ('to keep calm'/'to take it well') applies; there is therefore an additive relation between the topics of utterances (6a) and (6e) that is marked by auch. This shows that the notion "CONTRASTIVE topic" only makes sense on the GLOBAL level of discourse organization. Locally, there is nothing contrastive in the topic of $(6 e)-$ it is just the same as the one in the previous utterance and can therefore remain implicit under certain circumstances. Furthermore, terms like "bridge accent" or "I-topicalization" turn out to cover only a special case of this more general information structure. They cannot apply to the (6e) utterance, since the element that should carry the rising part of the intonation pattern is not actually realized at surface structure.

What we find in (6e) then is a given state of affairs that is claimed to be valid for a GLOBALLY CONTRASTIVE, yet at the same time LOCALLY GIVEN topic element. This might be the reason why the additive word itself carries the main stress. The (empty) topic part cannot do it, and with a normal focus intonation as in $\left(6 \mathrm{e}^{\prime}\right)$ one would unsuccessfully look for a contrast between the accent-marked state of affairs and a previously given one:

(6) $\mathrm{e}^{\prime}$. ?und $[\emptyset]$ hat es schließlich ziemlich LOcker genommen. 'and finally took it rather well'

Stressed auch explicitly blocks the search for a contrast in the following part of the information structure. But there are other reasons for the pitch accent on auch than just the deaccenting of the other information parts. The stress on the additive word indicates contrast as in the other cases. There is an open alternative with respect to the link between the given state of affairs and the topic element. $\left(6 \mathrm{e}^{\prime \prime}\right)$ would be a felicitous continuation of the discourse in (6a)-(6d) in case the state of affairs under discussion ('to take it well') had not applied to the entity talked about ('her father'):

(6) $\mathrm{e}^{\prime \prime} .[\emptyset]$ hat es aber GARnicht locker genommen.

'but (he) didn't take it well at all'

In $\left(6 \mathrm{e}^{\prime \prime}\right)$, negation expresses an alternative value for the link between the given state of affairs and a second topic. Like the additive particle above, it therefore carries the main stress.

\section{Topics and additive words in German}

Up to this point our discussion has focused on the additive scope particle auch and the pitch accent it carries when applied to a topic element as 
compared to the unstressed particles that go with focused pieces of information. While other types of German particles are stressed in very restricted contexts only (e.g. whiskey und NUR [whiskey] ... ('whiskey and only whiskey ...') or do not allow for a pitch accent at all, (e.g. *soGAR 'even') the additive particle noch 'also/another' shares the behavior of auch with respect to the existence of a stressed and an unstressed variant, the choice of which crucially depends upon the type of information structure the particle is integrated into. Furthermore, such a distinction can also be observed for temporal adverbials like (immer) noch 'still' and wieder 'again'. As with auch, different interpretations of the distinction between stressed and unstressed versions have been discussed in the literature. ${ }^{4}$

In what follows I shall propose that the information-structural conditions for a stressed auch outlined in section 2 can also account for cases in which the other particles and adverbials carry a pitch accent. As with a stressed auch, the common denominator is that the validity of a given state of affairs with respect to some different topic must be under discussion. But while auch is relatively open regarding the kind of topic information in its domain of application, stressed (immer) noch and wieder are confined to be applied to topic times (cf. Klein 1994), that is, the time span that the utterance makes a claim about. In the following example, I shall systematically compare the additive words with respect to the impact they have on the relation that is claimed to hold between a state of affairs and a topic. In (7a)-(7e) the (unstressed) additive words immediately precede their (focused) domains of application, which carry the main accent of the utterance. (7A)-(7E) contain the same sentences with a different stress pattern. The additive word itself carries the main accent of the utterance and its domain of application is one of the topic elements of that utterance. ${ }^{5}$

(7) a. er war auch [im instiTUT].

'he was also at the institute' (in contrast and in addition to being somewhere else)

A. [er] war $A U C H$ im institut.

'he was also at the institute' (in addition to one or more other [topic] persons that were claimed to be at the institute)

b. gestern war er auch [im instiTUT].

'yesterday he was also at the institute' (in contrast and in addition to being somewhere else)

B. [gestern] war er $A U C H$ im institut.

'yesterday he was also at the institute' (in addition to one or more other topic times at which he was claimed to be at the institute) 
c. am nachmittag besuchte er noch [ein instiTUT].

'in the afternoon he also visited an institute' (in contrast and in addition to visiting [or doing] something else $)^{6}$

C. [am nachmittag] besuchte er $\mathrm{NOCH}$ ein institut. 'in the afternoon he visited another institute' (in addition to one or more earlier topic times at which he was claimed to visit an institute)

d. um drei war er noch [im instiTUT]. 'at three he was still in the institute' (in contrast to the possibility of being somewhere else and in continuative addition to an earlier situation of being at the institute)

D. [um drei] war er immer noch ${ }^{7}$ im institut. 'at three he was still in the institute' (in continuative addition to one or more earlier topic times at which he was claimed to be in the institute)

e. um drei war er wieder [im instiTUT]. 'at three he was back at the institute' (in contrast to the possibility of being somewhere else and in [noncontinuative] addition to an earlier situation of being at the institute)

E. [um drei] war er WIEder im institut.

'at three he was at the institute again' (in [noncontinuative] addition to one or more earlier topic times at which he was claimed to be at the institute)

In (7A)-(7E), there is no contrast in the state of affairs ('being at/visiting an institute') that is claimed to hold for the topic. These utterances are therefore interpreted as repeated assertions, that is, as new instances of given states of affairs that are claimed to hold for the topic given in the utterance in addition to some other topic element. This is precisely why we get a repetitive (7E) instead of a restitutive (7e) interpretation for stressed wieder (see Klein 2001) and why a stress on noch, (7C), seems to indicate that "the alternative value can simply be another quantity or instance of the same kind" (König 1991: 153). In the present account this "addition of instances of the same kind" ('institutes' in [7C]) is explained as a consequence of the addition of topic times (or instances) for which the given state of affairs ('visiting an institute') is said to be true. ${ }^{8}$

It depends, then, on the basic meaning of the stressed additive word as to which kind of relation is said to hold between the two topic elements in question (cf. the difference between immer noch - continuative validity of the given state of affairs - and wieder - noncontinuative validity of the given state of affairs). In what follows, I shall only be concerned with 
the stressed, topic-related variants of the additive words auch, noch, immer noch, and wieder.

\section{Additive words and the expression of assertion in adult learner varieties}

In the preceding sections, topic-related additive words have been shown to modify the way in which states of affairs and topic information are related. This is the relation of assertion expressed through finiteness: the state of affairs holds for a given topic entity at a given time span. Klein (1998) assumes an abstract assertion operator that is projected on finiteness in many (fully fledged) languages: assertion marking is understood as a means of expressing that the relation between a state of affairs and a topic has some (positive or negative) value that can be checked against reality. Nonfinite utterances, on the other hand, just cannot be judged to be true or false. This is best seen in stressed finite auxiliaries that have almost no lexical meaning and just encode that the state of affairs rendered by the expressions in their scope does indeed hold for some given topic element - in contrast to the possibility that this might not be the case.

In case a given state of affairs is said to apply to more than one topic, the function of additive words and the function of finiteness marking seem therefore to be closely related. In such a context of repeated assertion as expressed by stressed auch, the simple assertive relation can even be seen as redundant.

This view is supported by striking observations of adult secondlanguage acquisition. Contrary to what is possible in the target language, untutored adult learners of German as a second language beyond the nonfinite basic-variety stage show a tendency to use stressed, topic-related auch and finiteness marking (e.g. finite auxiliaries) in complementary distribution. In example (8) (taken from the ESF database; see Perdue 1993) in which a learner is recounting the contents of a film, auch and finite auxiliaries are shown in italics:

(8) a. sie ist mit polizei geschimpft

'she has with police argued'

b. und die sind aus dem wagen 'and they are out of the car'

c. die sind runnergefallen von dem wagen 'they have fallen out of the car'

d. und [der mann] $A U C H$ runtagefallen 'and the man also fallen' 
e. die polizei und Chaplin und die mädchen die drei sind runtergefallen

'the police and Chaplin and the girl the three of them have fallen'

f. und die mädchen und der Chaplin sind aufgestanden

'and the girl and Chaplin have gotten up'

g. und [die polizei] $A U C H$ aufgestanden

'and the police also gotten up'

h. dann die Chaplin hat ihn über den kopf geschlagen ...

'then Chaplin has hit him on his head ...'

(Cevdet, II)

'She (= the girl) had an argument with the policeman and both of them fell out of the van, and the man (=Charlie Chaplin) also fell, so the policeman and Chaplin and the girl - the three of them have fallen out of the van. And the girl and Chaplin got up, and the policeman got up, too, and then Chaplin hit him on his head.'

In the light of the overall length and complexity of the utterances displayed in example (8), mere processing reasons do not seem to be a very plausible explanation for these cases of backsliding to a nonfinite utterance organization whenever topic-related auch is involved. ${ }^{9}$ The abovementioned conceptual relation between assertion marking through finiteness and these additive words, however, could possibly account for the fact that - even in relatively advanced learner varieties - assertion apparently does not deserve an independent expression in utterances with stressed auch.

At some interval - short and unstable as it might be - of the acquisition path toward a target-like integration of additive words, topicrelated auch and - as we shall see - other additive words are thus able to oust the overt expression of assertion. Their ability to incorporate the abstract assertion operator might be one of the reasons why adult secondlanguage learners acquire them quite early.

Learners of German normally start out with auch (as the less restricted of the additive words discussed in section 3), as do children in firstlanguage acquisition (see Penner et al. 1999 and Hulk forthcoming). At the nonfinite basic-variety stage, the expression of a (repeated) assertion and topic-related additive words do not yet run into any conflict since overt assertion marking is simply absent. However, learners' need to mirror information structure and the absence of hierarchical syntactic organization at this stage put severe positional restrictions on topicrelated additive words: their actual scope can only be marked by a position adjacent to their domain of application. 
Despite their functional correspondence on the information-structural level, topic-related additive words and assertion marking do come into conflict at later stages of acquisition. When assertion marking with the help of finiteness becomes increasingly obligatory, this has important structural ramifications for utterance organization. Due to the V2 constraint, additive words cannot be placed directly adjacent to their topical domain of application in target-adequate finite utterances. As we shall see, learners develop several intermediate solutions for the integration of additive words in finite utterances before target-language syntax finally outweighs the reflection of information structure. The backsliding into a nonfinite utterance organization as in example (8) is but one such intermediate solution on the way to a target-adequate postfinite position for topic-related additive words.

The acquisition data from contexts of repeated assertion that are presented in the following sections allow us to trace the acquisition process from a stage of functional and formal correspondence between the abstract assertion operator and topic-related additive words to a point where this functional correspondence goes along with a formal clash between the two.

\section{Data from an "additive-elicitation task" 10}

Empirical studies of information-structure-sensitive items in natural speech production frequently face the problem of unclear contexts: the domain of application of additive words is not always unambiguous, alternatives to some contrasted piece of information might not have been spelled out explicitly, etc. A reduction to controllable question-answer pairs, on the other hand, risks overinterpreting the role of some particularities of that special setting, which are in fact much less important in natural spoken discourse (cf. the discussion of contrastive topics in section 2). The "additive-elicitation task" presented in this section can be seen as resulting from the attempt to combine the advantages of relatively natural discourse data with the possibility of keeping the distribution of information under control.

In this task subjects were asked to perform an online narration based on a picturebook; they were always shown only one picture at a time; they told the corresponding part of the story and then continued on to the next picture by turning pages.

The stimulus used for the "additive-elicitation task" was created to fulfil the following three requirements: it had to (i) be simple and focused enough to control for the underlying information structure and make 
results from different speakers comparable, (ii) provide conditions for topic management that are nondeviant from the default case in that kind of discourse (narrative), and (iii) contain more or less obligatory contexts for the use of the topic-related additive words discussed in section 3 .

The whole picturebook consists of 30 single pictures: four introductory pictures accompanied by some explanation from the interviewer, and the actual story made up of three additive episodes (3-8 pictures each) and filler pictures.

\section{Introduction}

Subjects were first presented with the introductory pictures one by one, accompanied by some explanation given by the interviewer. The first picture shows an empty street with a church, a restaurant, and an armourer's shop. At one end of the street there is a hill with a forest and a path that leads up the hill to a castle. With non-native speakers this picture served to introduce the vocabulary needed later on. Furthermore it "set the scene" or introduced the (topic) place where the whole story plays.

Subjects were then told that a crime had happened in that little town on a Thursday evening and they were shown the second introductory picture. This picture shows the dead body of a young woman lying near the castle with a hatchet beside the corpse. The interviewer then told the subjects that there were only two suspicious people around in town. These are called Red and Blue (they actually differ only in color) and they are shown in the last two introductory pictures.

Subjects were then told that, luckily enough, they had observed Red and Blue through their window on that particular Thursday afternoon, and they were then asked to give a witness report. In order to inform the police, they were asked to answer the following (text) question: "What were Red and Blue doing when you saw them on Thursday afternoon?"

This text question, or quaestio (cf. von Stutterheim 1997), shapes the information structure of the main-structure utterances of the following discourse. Main-structure utterances are those utterances that reply to the quaestio in taking over the topic information given there and specifying some state of affairs with respect to this topic information. Note that in the question asked in the beginning of the additive-elicitation task, the two topic domains discussed before, namely topic time and topic entity, are explicitly set on a global and on a local level; the global topic time is the relevant Thursday afternoon, and the local topic times are the moments when the witnesses had seen the suspicious persons. On the 
global level, the entity talked about is the suspects, locally it is either Red or Blue. Each main-structure utterance will then have to specify a state of affairs that holds for one of the suspects for one moment within the global topic time.

After this introductory part, subjects are shown one picture at a time. On the following pictures, Blue is leaving Red in front of the church, and Red walks along the street toward the restaurant. Then he sits down at a table and drinks a beer. After this first scene, there is a series of pictures with either Red or Blue, so that locally the two topic domains (time and protagonist) follow their own prototypical referential movement from utterance to utterance. If nothing else is said, the protagonist is maintained from the previous utterance and the topic time is shifted from one utterance to the other (following the principle of natural order), while the state of affairs is constantly changing as the narration unfolds.

The pictures 1-30 are listed in Table 1. Topic time, topic entity, and state of affairs are indicated for every picture. In order to provide obligatory contexts for the use of additive words, the story line contains three "additive episodes" with additive relations between topic elements and a repetition of some state of affairs (marked I-III in the left column).

\section{Additive episode I (pictures 8, 20-22, 25-28)}

The first additive episode consists of a series of two times four pictures. The first set shows Red drinking a beer (8), later entering the armourer's shop (20), then coming out with a hatchet in his hand (21), and then walking up the hill into the forest (22). This series is followed by some fillers in which Blue does several things $(23,24)$, before he drinks a beer (25), enters the armourer's shop (26), then comes out with a hatchet in his hand (27), and then walks up the hill into the forest (28), too. Here, four subsequent states of affairs are first claimed to be true for one protagonist; and later, the same series applies to the second protagonist. The local conditions for movement within the topic domain still follow the default, and even the state of affairs changes locally. But the same states of affairs have already occurred earlier in the discourse, and native speakers mark these repetitions with the topic-related additive word auch (stressed form).

\section{Additive episode II (pictures 8-10)}

The second additive episode consists of three pictures only. In picture 8, Red sits at a table in front of the restaurant and drinks a beer. In the 
Table 1. The additive elicitation task picture series

\begin{tabular}{|c|c|c|c|c|c|}
\hline Add. & Picture no. & Topic time & Topic entity & State of affairs & Particle \\
\hline & \multicolumn{5}{|c|}{ 01-04: introduction of situation, place, and characters } \\
\hline & 05 & past & Red \& Blue & stand in front of the church & $\emptyset$ \\
\hline & 06 & shift & Blue & leave & $\emptyset$ \\
\hline & & maint. & Red & stand in front of the church & \\
\hline & 07 & shift & Red & walk toward the restaurant & $\emptyset$ \\
\hline I/II & 08 & shift & Red & drink a beer & $\emptyset$ \\
\hline II & 09 & shift & Red & drink a beer & noch \\
\hline \multirow[t]{5}{*}{ II } & 10 & shift & Red & drink a beer & noch \\
\hline & 11 & shift & Red & leave & $\emptyset$ \\
\hline & 12 & break & Blue & walk along the street & $\emptyset$ \\
\hline & 13 & shift & Blue & smoke a cigarette & $\emptyset$ \\
\hline & 14 & shift & Blue & leave by bus & $\emptyset$ \\
\hline III & 15 & 15.00 & Red & sit on the bench & $\emptyset$ \\
\hline III & 16 & 15.30 & Red & sleep on the bench & $\emptyset$ \\
\hline III & 17 & 16.00 & Red & sleep on the bench & noch \\
\hline III & 18 & 16.30 & Red & sit on bench, read newspaper & $\emptyset$ \\
\hline III & 19 & 17.00 & Red & sleep on the bench & wieder \\
\hline I & 20 & shift & Red & enter armourer's shop & $\emptyset$ \\
\hline I & 21 & shift & Red & leave armourer's shop with hatchet & $\emptyset$ \\
\hline \multirow[t]{3}{*}{ I } & 22 & shift & Red & walk into the forest & $\emptyset$ \\
\hline & 23 & break & Blue & arrive by bus & $\emptyset$ \\
\hline & 24 & shift & Blue & walk toward the restaurant & $\emptyset$ \\
\hline I & 25 & shift & Blue & drink a beer & auch \\
\hline I & 26 & shift & Blue & enter armourer's shop & auch \\
\hline I & 27 & shift & Blue & leave armourer's shop with hatchet & auch \\
\hline \multirow[t]{5}{*}{ I } & 28 & shift & Blue & walk into the forest & auch \\
\hline & 29 & shift & Blue & walk towards the castle & $\emptyset$ \\
\hline & & maint. & Red & stand in the forest & auch \\
\hline & 30 & shift & Blue & come close to the castle & $\emptyset$ \\
\hline & & maint. & Red & cut trees with hatchet & \\
\hline
\end{tabular}

next picture (9), he drinks a second beer, and then, in 10, a third one. The on-line narration prevents subjects from referring to this situation by just saying that Red had three beers, because when they see the initial picture they cannot know that other beers will follow.

The information structure underlying this scene is similar to additive episode I. There is no contrast in the state of affairs (here it is even repeated immediately) and no contrast in the domain of the topic entity. A given state of affairs holds true for one protagonist at three different times (topic-time contrast). Once more, the local topic conditions are default; there is a shift in topic time, and maintenance of the protagonist. Native speakers use the topic-related, stressed additive word noch in 
order to make clear that they are talking about different instances of beer drinking that take place at subsequent topic times.

\section{Additive episode III (pictures 15-19)}

The third additive episode involves an explicit topic-time shift since it is a close-up of the church that allows subjects to see the clock. In this episode Red sits on a bench (15), in the next picture (16, which is shown to be half an hour later) he sleeps on that bench. Half an hour later (17) he is still sleeping; then (18) again half an hour later, he sits on the bench reading a newspaper before (19, half an hour later) he is sleeping once more.

Again, what has to be expressed is that a given state of affairs is true for the topic entity at different times. However, the relation between these times differs within this episode. First we have an uninterrupted sleeping event (16-17) that native speakers refer to with the help of the topic-related additive word immer noch 'still', and then an interrupted (or repetitive) sleeping event (16/17-19) where the additive word wieder (again) must be used. In order to create the topic-related reading, both additive words have to be used in their stressed form.

\section{Subjects}

Subjects were 40 untutored adult learners of German with Russian (31), Turkish (6), and Croatian (3) as a first language ${ }^{11}$ and eight native speakers of German. The learners' length of stay in Germany varied between one and over 20 years. According to their overall levels of proficiency (judged on a basis of the utterance structure displayed in the narrative task and in about five minutes of informal talk before the experiment), learners were put into one of three groups. This ranking was mostly oriented around finiteness marking as a factor that had proved to be crucial for the integration of these particles (see Dimroth and Watorek 2000; Perdue et al., this issue). Thus, level 1 (8 learners) corresponds to the basic variety with its nonfinite utterance organization (less than $10 \%$ finite verbs in verb-containing utterances); group II (15 learners) represents a transitional phase with some variation in the degree of finiteness marking; and level III (17 learners) is near-native with respect to utterance organization (with above $90 \%$ finite verbs in verb-containing utterances). However, utterances at level III contain fewer constituents than native-speaker utterances, the verb-second rule of German declara- 
tive main clauses is not always applied, and there is almost no subordination.

\section{Results}

Section 6 contains three parts. In section 6.1 it is shown how learners who do not yet dispose of the relevant additive words express additive relations between topics by mere repetition of states of affairs and thereby spell out explicitly what the underlying information scaffolding looks like. Section 6.2 contains results from learners' and native speakers' choice of additive words with respect to the different topical domains of application. In section 6.3 is discussed how learners, in a step-by-step process, integrate additive words into the unfolding utterance structure, and which role the acquisition of finiteness plays in this respect.

\subsection{Additive episodes in learner varieties without additive words}

While advanced learners and native speakers of German tend to mark all the additive episodes with (the appropriate) additive words, secondlanguage learners who have not yet acquired auch, noch, immer noch, or wieder communicate the additive relation between topic elements merely by means of repetition of the state of affairs that holds true for these topics. Eight of the 40 narrations by second-language learners (from proficiency levels I and II) are constructed without topic-related additive words. The topic elements are thereby often left implicit.

Example (9) is an example of the first additive episode. First Red, and later Blue, enter the armourer's shop (lines 20 and 26), and then leave in the direction of the forest (lines 21 and 27). In this and all the following examples from the additive-elicitation task, each line corresponds to what has been said about one picture. The superscript numbers at the beginning of the lines refer to the numbers of the pictures as displayed in Table 1.

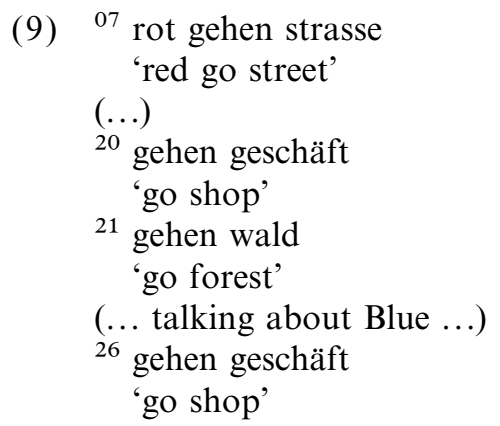


${ }^{27}$ gehen wald 'go forest' $(\mathrm{rg} 31)^{12}$

'Red walked along the street. (...) He went to the shop, and to the forest. (... Blue) went to the shop, and then to the forest.'

Example (10) from the second additive episode has a similar structure. The state of affairs that is supposed to be true for three consecutive yet different times is simply repeated three times over; that is, what is said with respect to the pictures 8,9 , and 10 is identical:

(10) (talking about Red)

$$
\begin{aligned}
& 08 \text { *bira* trinke }{ }^{13} \\
& \text { 'beer drink' } \\
& 09 \text { *bira* trinke } \\
& \text { 'beer drink' } \\
& 10 \text { *bira* trinke } \\
& \text { 'beer drink' }(\operatorname{tg} 05)
\end{aligned}
$$

'He was drinking a beer. He was drinking a beer. He was drinking a beer.'

Example (11) refers to the same episode, but the learner here sticks to a lexical solution that helps her to express that she is talking about three subsequent beer-drinking events: ${ }^{14}$

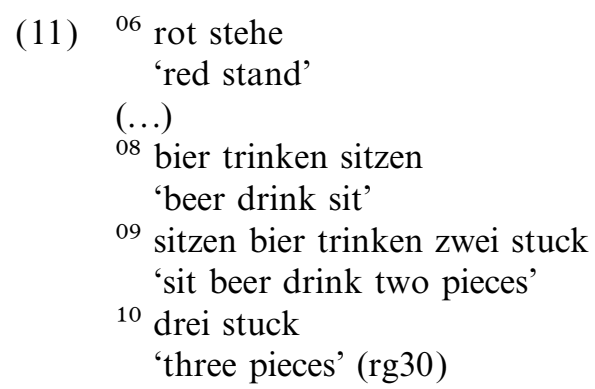

'He was drinking beer and sitting there. He was sitting there and drinking beer, two of them. Three of them.'

Like examples (9) and (10) above, (12) is an example of a cumulative strategy, applied here to additive episode III, whereby 'sleeping' (line 16) cannot be differentiated from 'still sleeping' (line 17) or from 'sleeping again' (line 19).

(12) (talking about Red)

${ }^{15}$ mann bank sitze 'man bench sit' 


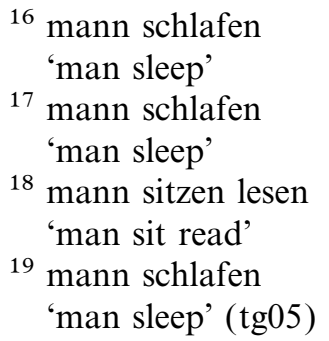

'The man was sitting on the bench. He was sleeping. He was sleeping. He was sitting and reading. He was sleeping.'

The learner in example (13) refers to the same episode without additive words. But instead of mere repetitions of protagonist and state of affairs, he follows two different strategies of lexical solutions. The first strategy consists of making similar situations lexically different (lines 16 and 17), the second strategy consists of making the topic element, for which the given state of affairs holds true, explicit (as in 19).

$$
\begin{aligned}
& 15 \text { rot mann sitzen sessel } \\
& \text { 'red man sit armchair' } \\
& 16 \text { *patom* liegt schlafen } \\
& \text { 'then lies sleep' } \\
& { }^{17} \text { schlafen *i chrape* } \\
& \text { 'sleep and snores' } \\
& 18 \text { halb fünf stehen } \\
& \text { 'half past four stand' } \\
& { }^{19} \text { fünf uhr schlafen } \\
& \text { 'five o'clock sleep' (rg04) }
\end{aligned}
$$

'Red was sitting in an armchair. Then he was lying down and sleeping. He was sleeping and snoring. At half past four he got up. At five o'clock he was sleeping.'

The above examples from elementary learner varieties that lack the means of expressing repeated information and additive relations in a condensed and economical way allow direct insights into the underlying information scaffolding. They show that the effect of topic-related additive words can be spelled out by reference to one state of affairs that is linked to different (mostly implicit) topics by mere repetition of mention.

\subsection{Additive words and their domains of application}

In this section, results on learners' and native speakers' choice of additive words in relation to the different types of topical domains of application 
Table 2. Number of topic-related additive words per groups of speakers

\begin{tabular}{lcc}
\hline Group & Speakers & Topic-related additive words \\
\hline I & 8 & 19 \\
II & 15 & 51 \\
III & 17 & 86 \\
Native & 8 & 33 \\
$\Sigma$ & 48 & 189 \\
\hline
\end{tabular}

are presented in quantitative terms. Only main-structure utterances, that is, utterances that are answers to the text question (or quaestio) mentioned in section 5 are considered here. Table 2 gives an overview of the quantity of additive words used by the different groups of speakers in the additiveelicitation task. Only additive words that clearly apply to topic elements and express that the given state of affairs holds for at least one more topic element of the same type (cf. section 2) have been considered.

It is important to note here that over $90 \%$ of the topic-related additive words used by the learners carry the main stress of the utterance, as is required in the target language. Even in the beginning stages of acquisition, learners prove to be sensitive to these differences of intonation. As we shall see later, this can be explained by the fact that in the absence of positional flexibility, stress is their only means of indicating that an additive word is to be applied to the topic information of the relevant utterance.

While the learners' behavior with respect to intonation was targetadequate, they had some problems choosing the correct additive words. Table 3 shows which of the additive words were used for the different topical domains of application by L2 learners and native speakers. "TT" and "TE" stand for topic time and topic entity, respectively.

One difference between learners and native speakers concerns the application of the additive particle auch to expressions referring to topic times. This is in principle possible in the target language (cf. example [4] in section 1), but not felicitous in the contexts provided by the additiveelicitation task. All the occurrences of auch in the native-speaker data were therefore applied to topic entities, whereas learners also used auch to express an additive relation between two topic times for which a state of affairs was true. Examples (14) and (15) are from the additive episodes II and III respectively:

(14) ${ }^{08}$ da trinkt er ein bier 'there drinks he a beer' 
Table 3. Types of topic to which the additive words were applied

\begin{tabular}{lrl}
\hline & {$[\mathrm{TT}]$} & {$[\mathrm{TE}]$} \\
\hline L2 & 15 & 71 \\
$\quad$ auch & 43 & - \\
noch & 2 & - \\
immernoch $_{\text {wieder }}$ & 25 & - \\
$\Sigma$ & 85 & 71 \\
Natives & & \\
$\quad$ auch $^{\mathrm{b}}$ & - & 14 \\
noch & 6 & - \\
immernoch $_{\text {wieder }}$ & 10 & - \\
$\Sigma$ & 3 & 14 \\
\hline
\end{tabular}

a. There are a few occurrences of stressed nochmal 'once more' instead of wieder in the learner data. This lexical choice does not make any structural difference.

b. There are a few occurrences of stressed ebenfalls 'also' instead of auch in the nativespeaker data. This choice of a stylistic variant does not make any structural difference.

${ }^{09}$ [danach] $A U C H$ ein bier 'then also a beer' $(\operatorname{tg} 03)$

'Then he drinks a beer. Then he has also a beer.'

15 dies mann sitzet bank 'this man sits bench'

16 schlaft 'sleeps'

${ }^{17}\left[\mathrm{TT}_{\emptyset}\right]$ schlaft $A U C H$ 'sleeps also' (rg24)

'This man is sitting on the bench. $\mathrm{He}$ is sleeping. He is also sleeping.'

The other main difference between learners and native speakers can be observed in the distribution of noch and immer noch. With the exception of two occurrences of immer noch, this strong (stressed) form of the temporal adverb noch is not used by the learners. Besides some overuses of auch, like that in example (15), it is mostly replaced by a stressed noch as in (16).

(16) ${ }^{15}$ rote is sitze kerch 'red is sits church'

${ }^{16}$ da schlaft die bank 'then sleeps the bench' 
${ }^{17}\left[\mathrm{TT}_{\emptyset}\right]$ schlaft $N O C H$ im bank 'sleeps still in bench' (rg06)

'Red is sitting in front of the church. Then he is sleeping on that bench. He is still sleeping on the bench.'

However, these minor problems regarding the choice of the correct additive word aside, there are no structural differences between the acquisition of auch, (immer) noch, and wieder with respect to topical domains of application. In their stressed form, all of them can be applied to so-called contrastive topics that locally follow discourse-dependent default topic conditions and can therefore be left implicit.

In learners' or native speakers' utterances the additive word applies, in other words, to an empty element that has to be interpreted with the help of the rules of anaphoric linkage in discourse. This applies to cases of maintenance of reference to the protagonist and/or shift of reference to topic time, and the information can then be recovered from the preceding context (see example [15] and [16] above, where $\left[\mathrm{TT}_{\emptyset}\right]$ refers to some topic time that is after the topic time of the preceding utterance). Reference to topic time is more often left implicit than reference to the topic entity, and learners tend to leave more topic information unexpressed $(59 \%)$ than native speakers $(24 \%)$ do. But in both groups of speakers the number of implicit topic elements that function as domains of application of additive words corresponds to their overall quantity of implicit topics under the default conditions sketched above.

\subsection{The stepwise integration of additive words into the unfolding utterance structure}

This section provides a closer look at the steps in the learners' acquisition path that are represented by the three levels of proficiency. Longitudinal studies with different source- and target-language settings have shown that the lexical items used for both topic- and focus-related particles tend to be acquired relatively early. ${ }^{15}$ Furthermore, as shown in the previous section, the German stressed versus unstressed distinction did not pose any serious problems to the learners investigated in the present study.

However, the position of the additive words with respect to their topical domain of application and therefore the way in which the additive word's scope is expressed changes considerably as acquisition moves on. As mentioned in section 4, learners at different stages do not just put these additive words in different positions, it is rather the case that a new possible position first has to be developed by means of the acquisition 
of other target-language properties. This is due to the fact that these additive words, like other scope particles, are optional elements that are integrated into an independent initial structure (Dimroth and Klein 1996) that stays the same if the additive word is left out. The way in which an additive word might be integrated into an initial structure depends crucially on the structure itself. As the initial structure changes its shape in the course of language acquisition, the integration of additive words and the expression of their interaction with their domain of application may change as well. The acquisition step from nonfinite to finite utterance organization has thereby proved to be of major influence. For that reason, only utterances that contain an overt verb form are considered in this section.

The schema below gives an overview of the order of acquisition of the different patterns. The additive words under consideration go through the same developmental steps and are thus integrated in one figure. In the finite structures, "SoA" (state of affairs) is put into brackets since (parts of ) the expression(s) referring to the state of affairs may get fused with Fin, creating a finite lexical verb.

\section{Order of integration patterns}

no additive words $>[\mathrm{T}]$ AW SoA $\mathrm{Anfin}>[\mathrm{T}]$ AW Fin $(\mathrm{SoA})$
$\quad>[\mathrm{T}]$ Fin AW $(\mathrm{SoA})$

$[\mathrm{T}]=$ topical domain of application (time or entity)

AW $=$ additive word

SoA $=$ expression of state of affairs

Fin $=$ finite verb

As can be seen from this schema, once acquired, topic-related additive words are first placed right-adjacent to their domain of application, that is, between the expression of topic information and the expression of the relevant state of affairs. This means that they are in an utterance-initial position whenever the topic information is left implicit by some speaker. When finiteness marking comes in, two acquisition steps can be observed. First the additive word is kept adjacent to its domain of application. This is where it logically belongs, but the result is ungrammatical in the target language. As we shall see later, this step is a rather unstable transition phase before the additive word is then put into a targetadequate position to the right of the finite verb; thus integrated into the VP but without direct contact with its domain of application. Table 4 shows how the different patterns are distributed over the learners at the three levels of proficiency and the native speakers. 
Table 4. Additive topic particles in utterances containing verbs

\begin{tabular}{|c|c|c|c|}
\hline $\begin{array}{l}\text { Level } \\
\text { (no. of additive words) }\end{array}$ & $\begin{array}{l}{[\mathrm{T}] \mathrm{AW} \text { So } \mathrm{A}_{\text {nofin }}} \\
\text { no. }(\%)\end{array}$ & $\begin{array}{l}{[\mathrm{T}] \text { AW Fin (SoA) }} \\
\text { no. }(\%)\end{array}$ & $\begin{array}{l}{[\mathrm{T}] \text { Fin } \mathrm{AW} \text { (SoA) }} \\
\text { no. }(\%)\end{array}$ \\
\hline I (18) & $17(95)$ & $1 \quad(5)$ & 0 \\
\hline II (49) & $17(35)$ & $20(41)$ & 12 (24) \\
\hline III (80) & 2 (3) & 3 (4) & 75 (93) \\
\hline Natives (24) & 0 & 0 & $24(100)$ \\
\hline Total (171) & 36 & 24 & 111 \\
\hline
\end{tabular}

It can easily be seen in the first row that the structure [T] AW SoA $A_{\text {nonfin }}$ is clearly predominant at level I. Albeit less frequent, this structure is still used by the learners at level II (second row). But these learners, working on the acquisition of finiteness, do in fact use all of the structures. It is true that [T] AW Fin (SoA) is the most frequent one, but there is a lot of variation in this transition phase, since learners prefer different intermediate solutions in order to satisfy both the requirements of information structure and the requirements of the developing target-language syntax. Level III (third row) is characterized by a clear predominance of the target-adequate pattern [T] Fin AW (SoA), with the additive word at VP-internal position and no longer adjacent to its domain of application.

In what follows I shall discuss the properties of each developmental step separately and give some examples from the additive-elicitation task.

\section{Level I}

Here are some examples from learners at the first proficiency level. Example (17) is from the first and example (18) from the second additive episode. As with the other examples, the superscript numbers refer to the corresponding pictures of the additive-elicitation task (cf. Table 1 in section 5).

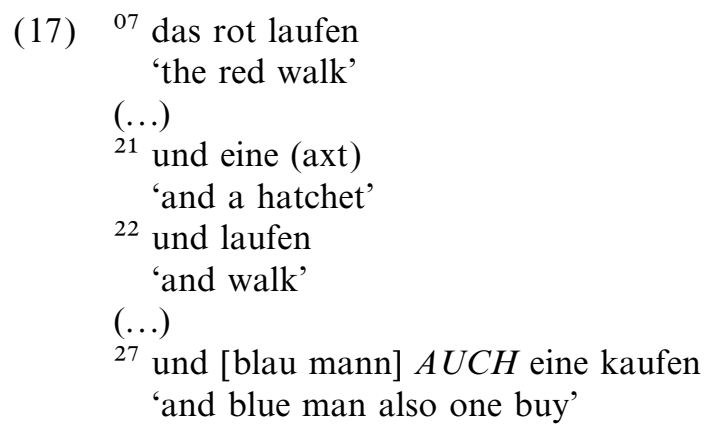


28

und $\left[\mathrm{TE}_{\emptyset}\right]$ AUCH laufen

'and also walk' ( $\operatorname{tg} 04)$

'Red was walking along the street. (...) He bought a hatchet and walked away. (...) Blue also bought one and he also walked away.'

${ }^{08}$ rote mann bier trinken

'red man beer drink'

${ }^{09}\left[\mathrm{TT}_{\emptyset}\right] \mathrm{NOCH}$ bier trinken

'still/another beer drink'

${ }^{10}\left[\mathrm{TT}_{\emptyset}\right]$ NOCH zuviel bier trinken

'still/another too much beer drink' (rg10)

'Red was drinking beer, he was drinking another beer and still a lot of beer.'

The most striking phenomenon at this level is that in nonfinite utterances only the word order under A is attested, while the other possible orders, $\mathrm{B}$ and $\mathrm{C}$, do not occur:
A. [T] AW SoA $A_{\text {nonfin }}$
B. [T] SoA $A_{\text {nonfin }}$ AW
C. AW [T] SoA ${ }_{\text {nonfin }}{ }^{16}$

Two reasons for this might be considered. First, the structure chosen by the learners allows them to keep the particle adjacent to its domain of application (this rules out structure B). In the absence of a hierarchical syntax, adjacency seems to be the only way to express which part of the utterance the additive word applies its meaning to. Second, if one considers the functional correspondence between topic-related additive words and the marking of the (assertive) relation between SoA and [T] structure A corresponds best to the underlying information structure topicassertion-SoA. In learner varieties based on a nonfinite utterance organization (the BV; see Klein and Perdue 1997), word order tends to mirror the underlying information structure more directly than more advanced varieties do. Together these reasons might explain why A is the only structure attested at level I as well as in nonfinite structures at more advanced levels of acquisition.

\section{Level II}

Though less frequently, learners of level II still produce additive words integrated into nonfinite initial structures. Since these are similar to the ones produced by level I learners, they will not be further discussed here. Once finiteness marking comes in, there seems to be a competition between the established correspondence between surface structure and 
information structure and the upcoming rules of target-language syntax. Two further developmental steps can be observed (cf. columns 3 and 4 of Table 4 above). Here I shall focus on the structure where the additive word is put between its topical domain of application and the finite verb: [T] AW Fin (SoA). This structure is the most frequent one exhibited at level II, and it is nearly absent from the other proficiency levels. These examples are taken from the first and the third additive episode; finite verbs are italicized.

${ }^{15}$ da ist rot mann 'there is red man'

(...)

20 er rennst in "waffenpaul"

"he runs into "waffenpaul", (=name of armourer's shop in the picture)

${ }^{21}$ er kaufen/kaufst (...) ein beil 'he buys a hatchet'

(...)

${ }^{23}$ blaumann fahrt mit dem bus

'blue man arrives by bus'

(...)

${ }^{26}$ [er] auch geht in waffenpaul 'he also goes into waffenpaul'

${ }^{27}$ und $\left[\mathrm{TE}_{\emptyset}\right]$ AUCH kauft beil 'and also buys a hatchet' (rg09)

'There is Red. (...) He runs into the armourer's shop and buys a hatchet. (...) Blue arrives by bus. (...) He also goes into the armourer's shop and buys a hatchet.'

(20) ${ }^{15}$ rote sitzt in bank 'red sits in bench'

${ }^{16}$ schlaft auf den bank 'sleeps on the bench'

${ }^{17}$ schlafen/lang schlaft 'sleeping/long sleeps'

18 steht auf und liest zeitung 'gets up and reads the newspaper'

19 [um fünf uhr] WIEDER schläft 'at five o'clock again sleeps' (rg27)

'Red is sitting on a bench. He is sleeping on the bench. He is sleeping for a long time. He gets up and reads the newspaper. At five o'clock he is sleeping again.' 
Consider the following explanation for this predominant pattern. Whereas the additive words are always adjacent to their domain of application in the basic nonfinite structure, in the target language they are separated from their domain of application by the finite element. In the transition phase discussed here, finiteness marking in a position between topic and state of affairs becomes more and more obligatory, but the additive words show a tendency to stay where they informationstructurally belong - adjacent to their domain of application. One could also argue that it is only gradually that the finite element takes over the assertion potential, that is, the role of a mediator between the validity of a state of affairs for some (different) topic; for a while it shares this function and the position between topic elements and the expression of the state of affairs with the additive word. This idea is supported by the fact that level II learners tend to slide back into a nonfinite utterance organization when topic-related additive words are present. Consider the following examples:

${ }^{23}$ blau mann fahrt zurück in dorf oder in stadt

'blue man drives back to the village or city'

${ }^{25}$ und [er] $A U C H+$ bier trinken

'and he also beer drink'

${ }^{26}$ dann hat er + in "waffenpaul" geschäft gegangen

'then has he in "waffenpaul" shop gone'

${ }^{27}$ und $\left[\mathrm{TP}_{\emptyset}\right]$ AUCH eine biel gekauft 'and also a hatchet bought'

${ }^{28}$ und $\left[\mathrm{TP}_{\emptyset}\right] A U C H$ in schlo $\beta+$ gegangen 'and also in castle gone' (rg21)

'Blue comes back to the town. He drinks a beer too. Then he entered "waffenpaul" and bought a hatchet, too. And then he also went to the castle.'

A similar complementary distribution of additive words and finiteness marking was already observed in example (8) in section 4, but there we only attested missing auxiliaries, while the following two examples illustrate that in the presence of additive words, even finite lexical verbs used by the learners within the same episode, can be turned back into infinitives (sitzen 'sit', schlafen 'sleep').

${ }^{07}$ rote mann geht ins restaurant 'red man goes into the restaurant'

${ }^{08}$ und er sitzt auf dem stuhl und trinkt bier (...) 'and he sits on the chair and drinks beer'

${ }^{09}$ er sitzt und trinkt 'he sits and drinks' 
${ }^{10}\left[\mathrm{TT}_{\emptyset}\right]$ AUCH sitzen und/ 'also sit and/' (rg13)

'Red enters the restaurant and he sits on a chair and drinks beer. He is sitting there and drinking. Then he also sits and/.'

(23) (talking about Red)

${ }^{15}$ hat neben schloß gesessen 'has besides the castle sat'

${ }^{16}$ hat geschlaft auf dem/ 'has slept on the/'

${ }^{17}\left[\mathrm{TT}_{\emptyset}\right]$ NOCH schlafen 'still sleep' (rg28)

'Red was sitting besides the castle. Then he was sleeping on the/ (??). He was still sleeping.'

Since there is a lot of variation with respect to the proportion and robustness of finiteness marking in this transitional phase, this phenomenon of backsliding to nonfinite utterances with additive words cannot be observed in all learners at level II.

However, both patterns attested at level II, namely (i) additive words and finiteness marking sharing the position between topic and state of affairs (examples [19], [20]), and (ii) additive words replacing finiteness marking (examples [21]-[23]), indicate that the principles "reflect information structure" and "respect target-language syntax" have run into a conflict here. It is only after different intermediate solutions of the type sketched above that learners finally acquire the target-language position for these additive words.

\section{Level III and native speakers}

The following examples from the three additive episodes illustrate that the structural integration of topic-related additive words is targetadequate at level III. Without exception, the additive words are integrated into the VP and finite elements are no longer dropped in the relevant utterances.

(24) (talking about Red)

${ }^{20}$ danach geht er in waffen 'and then goes he in "arms",

${ }^{21}$ er kauft (...) eine axt

(...)

'he buys a hatchet'

${ }^{23}$ dann kommt auf dem bus ein blaues mann 'then comes on the bus a blue man' 
$(\ldots)$

${ }^{26}$ und $\left[\mathrm{TE}_{\emptyset}\right]$ geht $A U C H$ zum waffenladen

'and goes also to the armourer's shop'

27 [er] hat AUCH axt gekauft

'he has also a hatchet bought' $(\operatorname{rg} 01)$

'Then Red enters the armourer's shop. He buys a hatchet. (...)

Then Blue arrives by bus (...) and goes to the armourer's shop too. He also bought a hatchet.'

${ }^{07}$ der rote geht in der restaurant

'the red goes into the restaurant'

${ }^{08}$ dann sitzt er er trinkt bier

'then sits he he drinks beer'

${ }^{09}$ [dann] trinkt er $\mathrm{NOCH}$ ein

'then drinks he still/another one' (rg23)

'Red goes into the restaurant. Then he is sitting there and drinking beer. Then he drinks another one.'

(26) (talking about Red)

16 dann schläft er (...)

'then he is sleeping'

${ }^{17}\left[\mathrm{TT}_{\emptyset}\right]$ schläft Immer noch 'sleeps still'

18 jetzt liest er zeitung 'now reads he the newspaper'

19 [dann] schläft er WIEder

'then sleeps he again' $(\operatorname{tg} 06)$

'Then Red is sleeping, and still sleeping. Now he is reading a newspaper. Then he is sleeping again.'

Minor problems with the correct forms of words aside, these utterances do not differ from the ones used by the native speakers for these additive episodes. The additive words are no longer found in a prefinite position, that is, adjacent to their topical domains of application. It is important to note that it is not only the acquisition of the German V2 rule that brings this new structure about. There are examples that violate the V2 rule by putting more than one topic expression (e.g. an adverbial and a pronoun) in front of the finite verb, and the additive word can still be found in a target-adequate postfinite position:

19 [dann] er schlaft $\mathrm{NOCH}(\mathrm{rg} 01)$

'then he sleeps still'

'Then he still slept.'

${ }^{19}$ [hier] er schläft $\mathrm{NOCH}(\mathrm{rg} 26)$

'here he sleeps still'

'Here he is still sleeping.' 
The new rules for the position of additive words within the VP cannot be caused by the strong syntactic constraint of the target language, which is supposed to reduce the syntactic positions available in front of the finite verb to just one. ${ }^{17}$ As illustrated by the examples above, in learners of level III, the finite verb can still be preceded by two topic elements, but the link between these complex topics and the relevant state of affairs is expressed by the finite verbs alone.

In more advanced learners, utterances with two explicit topics before the finite element become increasingly rare. Contrary to its informationstructural role, one of the topic elements must then be placed in a postifinite position. Topic elements in both initial position, (29), and postfinite position, (30), can function as a domain of application for the following additive words.

${ }^{19}$ [dann] hat er WIEDER geschlaft $(\operatorname{rg} 08)$ 'then has he again slept'

'Then he slept again.'

${ }^{27}$ dann hat [er] $A U C H$ eine axe genommen $(\operatorname{tg} 03)$

'then has he also a hatchet taken'

'Then he took a hatchet too.'

From examples like (27) and (28) we can conclude that at level III, topic-related additive words no longer compete with finiteness marking for the expression of the assertive relationship between a state of affairs and some topic element(s) even if the German V2 rule is not yet respected in all of the cases (in contrast to [29] and [30]).

\section{Conclusion}

In this article additive scope particles (auch, noch) and temporal adverbials (immer noch, wieder) have been viewed from an information-structurebased perspective. From this perspective, the stressed versus unstressed distinction was related to a special kind of interaction between these additive words and the underlying and in principle independent information structure of the relevant utterances. It was shown that the stressed versions of these additive words have scope over a domain of application that does not function as the focus, but rather as the topic of some utterance in context. In this respect, the additive particles and adverbials investigated form a homogeneous group; they express that one state of affairs holds for one topic time or entity in addition to a (often earlier mentioned or contextually given) different topic time or entity. 
We were able to confirm this homogeneous explanation by an analysis of discourse data from adult second-language learners of German at different levels of proficiency. Thanks to an "on-line" elicitation technique, the resulting data were at the same time natural and controlled for their underlying information structure. For the less advanced learners we showed that in the absence of finiteness marking only one position for topic-related additive words was available, namely the position between the topic element in the scope of the additive word and the expression of the state of affairs that is claimed to be true for this topic element. In the next stage of acquisition, finiteness seems to compete with additive words for this position. At this stage, due to their role as mediators between a repeated state of affairs and a (contrastive) topic, additive words can even comprise assertion marking and appear in complementary distribution with finiteness. Only at a stage with stable finiteness marking can additive words have distant scope over a topic element.

While the acquisition of finiteness has once more proved to be a milestone in language development and crucial for untutored learners' utterance organization, the stepwise integration of additive words might provide a more fine-tuned gauge within the overall development that goes from "mirroring the information structure" toward "adapting utterance organization to the rules of target-language syntax."

Received 10 January 2001

Revised version received

Max Planck Institute

22 June 2001

\section{Notes}

* Correspondence address: Max Planck Institute for Psycholinguistics, P.O. Box 310, 6500 AH Nijmegen, The Netherlands. E-mail: christine.dimroth@mpi.nl.

1. One could even argue that it is due to some problems with the planning of the utterance, since the speaker could have rendered the same situation in a much more economical way by just answering "Well, they didn't worry too much." But since question-answer examples of this type have the advantage of allowing for a high degree of control over the distribution of information involved, they have been widely discussed in the literature (cf. Büring 1995; Krifka 1999).

2. No other accent is marked in example (4). For a discussion of the so-called bridge accent, see section 2 .

3. This function of a VP-anaphor might be one of the reasons why the topic-related additive particle auch is attested so early in L1 acquisition data (cf. Penner et al. 1999). It allows children to link a (contextually) given situation to a different topic without explicitly referring to that situation. If the topic is salient enough, it might even be left out, too; a child seeing somebody eating an ice-cream and just uttering auch will probably be understood by its parents. 
4. See e.g. van der Auwera (1993), Nederstigt (2001) for noch, and Fabricius-Hansen (2001), von Stechow (1996), and Klein (2001) for wieder.

5. As pointed out before, these topical domains of application may carry a pitch accent, too. When no context is given, this marking might even be required in some cases.

6. In some cases, auch and noch are interchangeable (cf. [7a]). Sometimes they are even compatible: Ich war auch noch [im instiTUT] 'I was also at the institute'.

7. While the stressed counterpart of the additive scope particle noch is just $\mathrm{NOCH}$, the stressed counterpart of the temporal adverbial noch is immer noch.

8. The English translation another as in (7C) indicates, more clearly than the German word noch, which does not contain the idea of 'other' or 'different', that the two different instances of institute visiting must involve two different institutes, too.

9. Note that similar observations have also been made for first-language acquisition (Penner et al. 1999) and with respect to the integration of negation (Giuliano 2000).

10. Many thanks to Rainer Dietrich for his helpful comments on earlier versions of this method.

11. Many thanks to Karoline Dimroth, who helped me in finding and contacting the subjects, and, of course, to the subjects themselves.

12. The symbol "rg" refers to a Russian learner of German, "tg" to a learner with L1 Turkish, and "cg" to a learner with L1 Croatian. "gg" refers to German native speakers.

13. *..* marks forms from the learner's native language.

14. The second additive episode was actually the one where the use of additive words was avoided and replaced by lexical solutions ('a second beer ...') by some native speakers also.

15. See Perdue et al. (this issue) for details on the order of acquisition.

16. The initial position of the additive word even conforms to the target language, though not with the same kind of information structure.

17. Furthermore, it is completely unclear why (a) * [Paul] auch hat einen $B M W$ 'Paul also has a BMW' is a violation of the V2 principle, while (b) Auch [Paul] hat einen BMW is not. Sentences like (b) motivated Jacobs (1983) to speak about a V3 rule for German main clauses.

\section{References}

Benazzo, Sandra (2000). L'acquisition de particules de portée en français, anglais et allemand L2. Etudes longitudinales comparées. Unpublished doctoral dissertation, Université Paris VIII and Freie Universität Berlin.

Büring, Daniel (1995). The 59th Street Bridge accent. On the meaning of topic and focus. Unpublished doctoral dissertation, Universität Tübingen.

Dimroth, Christine (1998). Fokuspartikeln und Informationsgliederung im Diskurs. Unpublished doctoral dissertation, Freie Universität Berlin.

-; and Klein, Wolfgang (1996). Fokuspartikeln in Lernervarietäten. Ein Analyserahmen und einige Beispiele. Zeitschrift für Literaturwissenschaft und Linguistik 104, 73-114.

-; and Watorek, Marzena (2000). The scope of additive particles in basic learner languages. Studies in Second Language Acquisition 22, 307-336.

Fabricius-Hansen, Catherine (2001). Wi(e)der and again(st). In Audiatur Vox Sapientiae. A Festschrift for Arnim von Stechow, Caroline Féry and Wolfgang Sternefeld (eds.), 101-130. Berlin: Akademie Verlag. 
Giuliano, Patrizia (2000). L'acquisition et l'expression des fonctions négatives en français et en anglais comme langues secondes. Unpublished doctoral dissertation, Université Paris VIII and Università di Pavia.

Hulk, Aafke (forthcoming). Merging scope-particles. Word order variation and the acquisition of "aussi" and "ook" in a bilingual context. In Informationstructure, Linguistic Structure and the Dynamics of Acquisition, Christine Dimroth and Marianne Starren (eds.). Amsterdam: Benjanims.

Jacobs, Joachim (1983). Fokus und Skalen. Zur Syntax und Semantik von Gradpartikeln im Deutschen. Tübingen: Niemeyer.

- (1997). I-Topikalisierung. Linguistische Berichte 168, 91-133.

Klein, Wolfgang (1994). Time in Language. London: Routledge.

- (1998). Assertion and finiteness. In Issues in the Theory of Language Acquisition. Norbert Dittmar and Zvi Penner (eds.), 225-245. Bern: Lang.

-(2001). Time and again. In Audiatur Vox Sapientiae. A Festschrift for Arnim von Stechow, Caroline Féry and Wolfgang Sternefeld (eds.), 267-286. Berlin: Akademie Verlag.

-; and Perdue, Clive (1992). Utterance Structure. Developing Grammars Again. Amsterdam: Benjamins.

-; and Perdue, Clive (1997). The basic variety. Or: couldn't natural language be much simpler? Second Language Research 13(4), 301-347.

König, Ekkehart (1991). The Meaning of Focus Particles. London: Routledge.

Kowalski, Andrea (1992). Zur Syntax und Semantik von Gradpartikeln im Deutschen: Syntaktische Bedingungen für die Ausdehnung von Partikelskopus und -fokus. Unpublished MA thesis. Bergische Universität-Gesamthochschule Wuppertal.

Krifka, Manfred (1999). Additive particles under stress. Proceedings of SALT 8, 111-128. Ithaca, NY: Cornell University, CLC Publications.

Lambrecht, Knud (1994). Information Structure and Sentence Form. Topic, Focus, and the Mental Representations of Discourse Referents. Cambridge: Cambridge University Press.

Nederstigt, Ulrike (2001). The acquisition of additive focus particles in German. In Proceedings of the 25th Annual Boston University Conference on Language Development, Anna H.-J. Do, Laura Domínguez, and Aimee Johansen (eds.), 554-565. Somerville, MA: Cascadilla.

Penner, Zvi; Tracy, Rosemarie; and Wymann, Karin (1999). Die Rolle der Fokuspartikel AUCH im frühen kindlichen Lexikon. In Das Lexikon im Spracherwerb, Jörg Maibauer and Monika Rothweiler (eds.), 229-251. Tübingen and Basel: UTB Franke.

Perdue, Clive (1993). Adult Language Acquisition: Cross-Linguistic Perspectives. Cambridge: Cambridge University Press.

Reis, Marga; and Rosengren, Inger (1997). A modular approach to the grammar of additive particles: the case of German auch. Journal of Semantics 14, 237-309.

van der Auwera, Jan (1993). "Already" and "still": beyond duality. Linguistics and Philosophy 16, 613-653.

von Stechow, Arnim (1996). The different readings of wieder "again": a structural account. Journal of Semantics 13, 87-138.

von Stutterheim, Christiane (1997). Einige Prinzipien des Textaufbaus. Empirische Untersuchungen zur Produktion mündlicher Texte. Tübingen: Niemeyer.

Watorek, Marzena; and Perdue, Clive (1999). Additive particles and focus: observations from learner and native-speaker production. Linguistics 37(2), 297-323. 